\title{
Forecasting oil price volatility using spillover effects from uncertainty indices
}

\author{
Ioannis Chatziantoniou ${ }^{1}$, Stavros Degiannakis ${ }^{2,3,}$, Panagiotis Delis $^{2}$, George Filis ${ }^{4}$ \\ ${ }^{1}$ University of Portsmouth, Portsmouth Business School, Portland Street, PO1 3DE, UK. \\ ${ }^{2}$ Panteion University of Social and Political Sciences, Department of Economics and \\ Regional Development, 136 Syggrou Av., GR17671, Athens, Greece. \\ ${ }^{3}$ University Research Institute of Urban Environment and Human Resources, Panteion \\ University, 29 Aristotelous St., GR17671, Athens, Greece \\ ${ }^{4}$ University of Patras, Department of Economics, University Campus 265 04, Rio, \\ Patras, Greece. \\ *Corresponding author's email: s.degiannakis@ panteion.gr
}

\begin{abstract}
We consider spillovers between oil price volatility and key uncertainty indicators and we extend the applicability of the spillover index beyond economic inference, by generating forecasts of oil price volatility. The paper shows that spillovers do not contain significant predictive information, raising critical questions regarding the usefulness of the spillover index for forecasting exercises at low sampling frequency; i.e. for monthly data.
\end{abstract}

JEL codes: C22, C32, C53, Q47.

Keywords: Uncertainty, oil price volatility, forecasting accuracy, spillover effects. 


\section{Introduction}

Since the development of the Diebold and Yilmaz (2009) spillover index and the Baker et al. (2016) economic policy uncertainty (EPU), many studies have assessed the relationship between the latter and oil prices/volatility (Antonakakis et al., 2014; Kang et al., 2017). Others have examined the predictive information of EPU on oil price/volatility forecasts (Bekiros et al., 2015; Degiannakis and Filis, 2017, 2018). Findings suggest that EPU transmits spillover effects to the oil market and contains predictive information.

However, there are still two important gaps that need to be addressed: $(i)$ there exist different layers of uncertainty, EPU aside, which could also transmit spillover effects to oil prices/volatility (e.g. geopolitical uncertainty, financial markets uncertainty, etc.), that have hitherto largely been ignored and (ii) studies that investigate spillover effects do not assess their usefulness in predictions. By contrast, we opine that spillover effects should not merely be used for inference, but also for forecasting purposes.

We fill these gaps by (i) concentrating on the most important uncertainty indicators and (ii) extending the applicability of the spillover index beyond mere inference, to show its usefulness for forecasting purposes. We confine our interest in oil price volatility, given its quality to approximate uncertainty surrounding the oil market. In this letter, we only consider low frequency data (monthly) due to the availability of data for the majority of the uncertainty indices.

Results show that, all different types of uncertainty are linked to $O V X$, but only spillovers from USEPU contain significant in-sample predictive information. Nonetheless, even these spillovers from USEPU cannot provide any statistically significant incremental forecasting gains. This finding practically questions the effectiveness of spillover effects for volatility forecasts and thus, the usefulness of the spillover index in general. To strengthen our findings further evidence is required that would consider other asset classes (for both returns and volatilities) and also the different magnitudes of spillover effects.

The remainder of the paper is structured as follows. Section 2 presents data and methods, Section 3 discusses empirical findings and Section 4 concludes the study. 


\section{Data and methods}

\subsection{Data description}

We use monthly data (June, 2007 to February, 2019) for the OVX index (implied volatility index of WTI crude oil prices), the VIX index (implied volatility index of S\&P500 index), the US EPU (USEPU), the global EPU (GEPU), the geopolitical risk index $(G R)$ by Caldara and Iacoviello (2018) and the partisan conflict index (PC) by Azzimonti (2014). The data have been retrieved by CBOE (OVX and $V I X)$, Baker et al. (2016) (USEPU and GEPU), M. Iacoviello's personal website ${ }^{1}(G R)$ and Federal Reserve Bank of Philadelphia $(P C)$. The study period is dictated purely by data availability of the $O V X$ index.

\subsection{Methods}

Initially, we employ the Diebold and Yilmaz (2012) framework to extract net pairwise spillovers between uncertainty indicators $\left(V I X_{t}, U S E P U_{t}, G E P U_{t}, G R_{t}, P C_{t}\right)$ and $O V X_{t}$. We start with the generic form of a $p$-th order, $N$-variable Vector Autoregressive $(V A R)$ model:

$$
\mathbf{z}_{t}=\sum_{k}^{p} \boldsymbol{\Theta}_{k} \mathbf{z}_{t-k}+\boldsymbol{e}_{t}
$$

where, $\boldsymbol{z}_{t}$ is a vector of $N(=6)$ endogenous variables, $\boldsymbol{\Theta}_{k}$ with $k=1, \ldots, p$, are parameter matrices $[N \times N]$ and $\boldsymbol{e}_{t} \sim(\mathbf{0}, \boldsymbol{S})$ is a vector of disturbances, independent over time; although not necessarily i.i.d.. ${ }^{2}$ Finally, $t=1, \ldots, T$ is the time index. The standard moving average representation of the $V A R$ is:

$$
\boldsymbol{z}_{t}=\sum_{b=0}^{\infty} \boldsymbol{A}_{b} \boldsymbol{e}_{t-b}
$$

where, the $[N \times N]$ coefficient matrices $\boldsymbol{A}_{b}$ are recursively defined. We employ a generalized framework (i.e. see Koop et al., 1996; Pesaran and Shin, 1998) whereby, no specific ordering is required. The $H$-step-ahead forecast error variance decompositions (FEVDs) are given by:

$$
\boldsymbol{\varphi}_{i j, t}(H)=\frac{\sigma_{j j, t}^{-1} \sum_{t=1}^{H-1}\left(\boldsymbol{u}_{i}^{\prime} \boldsymbol{A}_{t} \boldsymbol{S} \boldsymbol{u}_{j}\right)^{2}}{\sum_{t=1}^{H-1}\left(\boldsymbol{u}_{i}^{\prime} \boldsymbol{A}_{t} \boldsymbol{S} \boldsymbol{A}_{t}^{\prime} \boldsymbol{u}_{i}\right)}
$$

\footnotetext{
${ }^{1}$ https://www2.bc.edu/matteo-iacoviello/gpr.htm.

${ }^{2}$ For the estimation of the VAR model, we assume a specific form for mean and variance vector, i.e. $(\mathbf{0}, \boldsymbol{S})$, but we do not need to specify the distribution of $\boldsymbol{e}_{t}$, as long as the independency over time holds. The assumption of normally distributed errors is required only for the statistical inference.
} 
where, $\sigma_{j j}^{-1}$ is the standard deviation of the estimated error term for the $j$-th equation of the $V A R$ model and $\boldsymbol{u}_{i}$ is a selection vector, which assumes the value of one for element $i$ and zero otherwise. $\boldsymbol{S}$ is the estimated variance matrix of vector $\boldsymbol{e}$. The $\boldsymbol{\varphi}_{i j}(H)$ matrix gives the input of variable $j$ to the FEVD of variable $i$. The main diagonal corresponds to idiosyncratic effects while, off-diagonal elements, to cross-variable effects. The normalised version of the matrix (i.e. due to $\sum_{j=1}^{N} \boldsymbol{\varphi}_{i j}(H) \neq 1$ ) is $\widetilde{\boldsymbol{\varphi}}_{i j, t}(H)=$ $\frac{\varphi_{i j, t}(H)}{\sum_{j=1}^{N} \varphi_{i j, t}(H)}$. Our main focus, though, is on the net pairwise spillover effects that can be obtained as:

$$
N P W S(H)=\widetilde{\boldsymbol{\varphi}}_{i j, t}(H)-\widetilde{\boldsymbol{\varphi}}_{j i, t}(H) .
$$

Next, we assess the predictive content of the net pairwise spillover effects on the OVX index. We start from the in-sample estimation, employing the HAR model ${ }^{3}$, which is extended in order to include information from the net pairwise spillover effects:

$$
\begin{aligned}
\log \left(O V X_{t}\right)= & \alpha_{0}+\alpha_{1} \log \left(O V X_{t-1}\right)+\alpha_{2}\left(3^{-1} \sum_{n=1}^{3} \log \left(O V X_{t-n}\right)\right) \\
& +\alpha_{3}\left(12^{-1} \sum_{n=1}^{12} \log \left(O V X_{t-n}\right)\right)+\alpha_{4} \log \left(U N C_{t-1}\right) \\
& +\alpha_{5} d\left(N P W S_{O V X-U N C, t-1}<0\right) \\
& +\alpha_{6} d\left(N P W S_{O V X-U N C, t-1}<0\right) \times \log \left(U N C_{t-1}\right)+\varepsilon_{t},
\end{aligned}
$$

where $\varepsilon_{t} \sim\left(0, \sigma_{\varepsilon}^{2}\right), \quad U N C_{t}$ denotes each one of the five alternative uncertainty indicators, $U N C_{t}:\left\{V I X_{t}, U S E P U_{t}, G E P U_{t}, G R_{t}, P C_{t}\right\}$, the $d\left(N S P W_{O V X-U N C, t}<0\right)$ is a dummy variable that takes the value of one when the uncertainty indicator $\left(U N C_{t}\right)$ is a net transmitter of spillover effects ${ }^{4}$ to $O V X$ and zero otherwise.

Next, we proceed with the real out-of-sample forecasting exercise. A recursive approach is used with an initial sample period of 40 monthly observations. The remaining 41 months are used for the real out-of-sample iterated forecasts. We consider $h$-months ahead forecasts for $h=1, \ldots, 12$. Henceforth, in order to estimate real out-ofsample forecasts, eq.5 is re-estimated as:

\footnotetext{
${ }^{3}$ The Heterogeneous AutoRegressive model (HAR) by Corsi (2009) is regarded as the best for modelling and forecasting asset price volatility (Degiannakis and Filis, 2017). Following Degiannakis and Filis (2019) we adjust the simple HAR model for monthly data considering the 1-month, 1-quarter and 1-year lags. For robustness, we estimate distributed lag models as well as autoregressive models, but the findings are qualitatively similar and available upon request.

${ }^{4}$ According to our estimation of spillover effects, an uncertainty indicator is a net transmitter when the net pairwise spillover index is below zero.
} 


$$
\begin{aligned}
\log \left(\text { OVX }_{t}\right)= & \alpha_{0}+\alpha_{1} \log \left(\operatorname{OVX}_{t-1}\right)+\alpha_{2}\left(3^{-1} \sum_{n=1}^{3} \log \left(O V X_{t-n}\right)\right) \\
& +\alpha_{3}\left(12^{-1} \sum_{n=1}^{12} \log \left(O V X_{t-n}\right)\right)+\alpha_{4} \log \left(U N C_{t-h}\right) \\
& +\alpha_{5} d\left(N P W S_{O V X-U N C, t-h}<0\right) \\
& +\alpha_{6} d\left(N P W S_{O V X-U N C, t-h}<0\right) \times \log \left(U N C_{t-h}\right)+\varepsilon_{t},
\end{aligned}
$$

The forecasts from eq.6 are then compared with the random walk (RW) model $\left(\log \left(O V X_{t}\right)=\alpha_{0}+\varepsilon_{t}\right)$ and the simple HAR model (for $\alpha_{4}=\alpha_{5}=\alpha_{6}=0$ ), based on the Mean Squared Predictive Error (MSPE) statistical function.

\section{Findings}

\subsection{Spillover effects}

Figure 1 illustrates the net pairwise spillovers between $U N C$ and $O V X$. Not surprisingly, $O V X$ is mainly a transmitter of shocks to $V I X$ and GEPU, especially after the oil price collapse period of 2014-2016 (in line with Antonakakis et al., 2014). The net transmitting character of $O V X$ on these two uncertainty indices can be justified by the fact that increased uncertainty in the oil market can affect stock market behaviour and economic policy uncertainty via several channels, such as the stock valuation channel, monetary channel, fiscal channel, output channel and investment uncertainty channel (see, for instance, Degiannakis et al., 2018; Antonakakis et al., 2017; Antonakakis et al., 2014). Such findings can be also justified by the fact that the oil market has become more financialised over recent years and thus the uncertainties between the oil and stock markets tend to become more interlinked.

Conversely, $O V X$ mainly receives from $P C$, which could be explained by the impact of the US political disagreement on aggregate investment (Azzimonti, 2018). More particularly, despite the fact that oil is not explicitly included in the discussion about the broader effects of partisan conflict, Azzimonti (2018) makes very clear that there is a negative impact of the US partisan conflict on aggregate investment, which subsequently, can be argued to affect oil prices, given the importance of the US economy to the oil market (Jiang et al., 2020).

As far as USEPU is concerned, evidence suggests that apart from the oil price collapse period, it is a net transmitter of shocks to $O V X$. Once again, we observe that another US-specific policy-related uncertainty index (following the $P C$ ) tends to transmit shocks to $O V X$. Such finding strengthens the argument that oil market uncertainty tends to be impacted by policy-related conditions in the US. 
The impact of $G R$ is less clear as it assumes both roles. Nevertheless, apparently $G R$ transmits spillover effects to $O V X$ during the oil price collapse period. We note that linkages between oil and geopolitical risk have been mentioned in the study by Caldara and Iacoviello (2018), whereby increased levels of geopolitical risk, which are typically associated with turbulence in oil producing countries, tend to amplify uncertainty in the oil market.

[Figure 1 here]

\subsection{Modelling and forecasting oil price volatility}

Table 1 presents the results from the in-sample modelling of $O V X$, which is the first step to evaluate the usefulness of spillover effects beyond economic inference. Results suggest that only spillover effects transmitted by USEPU contain useful insample predictive information on $O V X$. A plausible explanation of this may rest on the fact that USEPU is the most inclusive uncertainty index, as it is impacted by USspecific, global and geopolitical events, as well as, by uncertainty in financial markets and conflicts among the US political parties, congress, and the President of the US.

[Table 1 here]

Next, we investigate whether the in-sample gains from spillover effects transmitted by the $U S E P U$ improve the accuracy for $O V X$ forecasting. Table 2 provides evidence that, although, USEPU spillover effects provide some forecasting gains, yet these are not statistically significant ${ }^{5}$. Hence, we maintain that the spillover effects do not contain incremental predictive ability, either compared to the RW or the simple HAR model. Thus, the usefulness of spillover effects for forecasting purposes is questionable.

\section{[Table 2 here]}

We should note here that the main idea behind the development of the spillover approach was not to identify out-of-sample gains but rather to be used for economic inference. Although in this study we proceed one step further so as to assess whether spillover effects have the ability to identify out-of-sample predictive gains, it may well be the case that their usefulness for economic inference may not translate into forecasting ability. Even more, the fact that we do not observe any out-of-sample forecasting gains could be the result of the specific forecasting framework that we

\footnotetext{
${ }^{5}$ This is based on the Model Confidence Set of Hansen et al. (2011).
} 
utilise, given that we solely capture linear effects. Thus, a different forecasting framework could reveal the predictive ability of spillover effects.

Overall, the results of this study pave the path for a new strand in the relevant literature, as they practically suggest that spillover analysis - although important to the extent that we attain a better understanding of the underlying interrelations within a network of variables, may not always be useful when it comes to out-of-sample forecasting. The specific questions that emerge from our analysis of this particular topic and deserve further investigation in the future relate to (i) the extent to which a rather inclusive index (e.g., USEPU) performs better vis-à-vis indices that capture individual components of uncertainty and (ii) whether the framework of analysis per se (e.g., the specific asset class or forecasting framework) is restrictive and does not actually support the generalisation of the findings.

\section{Conclusion}

We generated forecasts of $O V X$ based on net spillovers between the variable itself and key uncertainty indicators. Findings provide strong evidence that spillovers do not generate real out-of-sample forecasting gains at low sampling frequency, casting doubt on the overall effectiveness of the spillover approach. Nonetheless, given that our findings, on this rather novel approach, are conditional on the specific question under investigation, we maintain that additional evidence is required, considering different asset classes (e.g. exchange rates), different sampling frequency (i.e. daily data) and alternative forecasting frameworks.

\section{References}

Antonakakis, N., Chatziantoniou, I. \& Filis, G. (2014). Dynamic spillovers of oil price shocks and economic policy uncertainty. Energy Economics, 44, 433-447.

Antonakakis, N., Chatziantoniou, I., \& Filis, G. (2017). Oil shocks and stock markets: Dynamic connectedness under the prism of recent geopolitical and economic unrest. International Review of Financial Analysis, 50, 1-26.

Azzimonti, M. (2018). Partisan conflict and private investment. Journal of Monetary Economics, 93, 114-131.

Azzimonti, M. (2014). Partisan conflict. Federal Reserve Bank of Philadelphia. Working paper series, No. 14-19.

Baker, S.R., Bloom, N. \& Davis, S. J. (2016). Measuring economic policy uncertainty. The Quarterly Journal of Economics, 131(4), 1593-1636. 
Bekiros, S., Gupta, R. \& Paccagnini, A. (2015). Oil price forecastability and economic uncertainty. Economics Letters, 132, 125-128.

Caldara, D. \& Iacoviello, M. (2018). Measuring geopolitical risk. FRB International Finance Discussion Paper, 1222.

Corsi, F. (2009). A simple approximate long-memory model of realized volatility. Journal of Financial Econometrics, 7, 174-196.

Degiannakis, S. \& Filis, G. (2017). Forecasting oil price realized volatility using information channels from other asset classes. Journal of International Money and Finance, 76, 28-49.

Degiannakis, S. \& Filis, G. (2018). Forecasting oil prices: High-frequency financial data are indeed useful. Energy Economics, 76, 388-402.

Degiannakis, S. \& Filis, G. (2019). Forecasting European economic policy uncertainty. Scottish Journal of Political Economy, 66(1), 94-114.

Degiannakis, S., Filis, G., \& Arora, V. (2018). Oil prices and stock markets: A review of the theory and empirical evidence. Energy Journal, 39(5), 85-130.

Diebold, F. X. \& Yilmaz, K. (2009). Measuring financial asset return and volatility spillovers, with application to global equity markets. The Economic Journal, 119(534), 158-171.

Diebold, F. X. \& Yilmaz, K. (2012). Better to give than to receive: Predictive directional measurement of volatility spillovers. International Journal of Forecasting, 28(1), 57-66.

Hansen, P.R., Lunde, A. \& Nason, J.M. (2011). The model confidence set. Econometrica, 79(2), 453-497.

Jiang, Y., Ren, Y. S., Ma, C. Q., Liu, J. L., \& Sharp, B. (2020). Does the price of strategic commodities respond to US partisan conflict? Resources Policy, 66, 101617.

Kang, W., de Gracia, F. P. \& Ratti, R. A. (2017). Oil price shocks, policy uncertainty, and stock returns of oil and gas corporations. Journal of International Money and Finance, 70, 344-359.

Koop, G., Pesaran, M. H. \& Potter, S. M. (1996). Impulse response analysis in nonlinear multivariate models. Journal of Econometrics, 74(1), 119-147.

Pesaran, H.H. \& Shin, Y. (1998). Generalised impulse response analysis in linear multivariate models. Economics Letters, 58(1), 17-29. 


\section{TABLES}

Table 1: The extended HAR model from eq.5.

\begin{tabular}{|c|c|c|c|c|c|}
\hline \multirow[b]{3}{*}{$\alpha_{0}$} & \multicolumn{5}{|c|}{ Uncertainty indicators } \\
\hline & VIX & USEPU & GEPU & GR & PC \\
\hline & $0.7465^{* *}$ & $2.3548^{* * * *}$ & $0.7955^{*}$ & 0.2603 & 1.6879 \\
\hline$\alpha_{1}$ & $1.0696^{* * *}$ & $1.0241^{* * *}$ & $1.0741^{* * *}$ & $1.0867^{* * *}$ & $0.9911^{* * *}$ \\
\hline$\alpha_{2}$ & -0.3241 & -0.2657 & -0.2754 & -0.2521 & -0.2711 \\
\hline$\alpha_{3}$ & 0.0158 & 0.0532 & 0.0906 & 0.0343 & -0.0012 \\
\hline$\alpha_{4}$ & 0.0359 & $-0.3581^{* * *}$ & -0.0825 & 0.0391 & -0.1643 \\
\hline$\alpha_{5}$ & 1.2481 & $-1.9705^{*}$ & -0.7068 & 0.1147 & 0.5481 \\
\hline$\alpha_{6}$ & -0.5274 & $0.4045^{*}$ & 0.1369 & -0.0237 & -0.0776 \\
\hline Adjusted $R^{2}$ & 0.7897 & 0.7971 & 0.7698 & 0.7657 & 0.7883 \\
\hline$F$-statistic & $43.5763^{* * *}$ & $45.5252^{* * *}$ & $38.9093^{* * *}$ & $38.0486^{* * *}$ & $43.2081^{* * *}$ \\
\hline$D W$ & 1.8946 & 2.0591 & 1.9223 & 1.9006 & 1.9351 \\
\hline$A I C$ & -0.6833 & -0.7188 & -0.5927 & -0.5751 & -0.6764 \\
\hline $\begin{array}{l}\text { Note: DW is } \\
\text { statistic tests } \\
\text { equal to zero } \\
\text { the uncertain } \\
\text { policy uncert } \\
*_{* *},{ }^{* * *} \text { deno }\end{array}$ & $\begin{array}{l}\text { Durbin-Watso } \\
\text { ull hypothesis } \\
\text { it is computed } \\
\text { dices for the } \\
\text { geopolitical } \\
\text { gnificance at }\end{array}$ & $\begin{array}{l}\text { statistic, AIC } \\
\text { that all the coe } \\
\text { as: } \mathrm{F}=\frac{\mathrm{R}^{2} /(\mathrm{k}-1}{\left(1-\mathrm{R}^{2}\right) /(\mathrm{T}} \\
\& \mathrm{P} 500, \mathrm{US} \text { ec } \\
\text { sk and partisa }\end{array}$ & $\begin{array}{l}\text { the Akaike } \\
\text { cients (exclu } \\
\text { VIX, USEI } \\
\text { omic policy } \\
\text { conflict, resp }\end{array}$ & $\begin{array}{l}\text { nformation Cr } \\
\text { ling intercept) } \\
\text { U, GEPU, GR } \\
\text { uncertainty, gl } \\
\text { ctively. }\end{array}$ & $\begin{array}{l}\text { iterion. The F } \\
\text { are statistically } \\
\text { and } \mathrm{PC} \text { denote } \\
\text { obal economic }\end{array}$ \\
\hline
\end{tabular}

Table 2: MSPE results based on the real out-of-forecasts; forecasting period: October 2015 - February 2019.

\begin{tabular}{cccccc}
\hline $\begin{array}{c}\text { Forecasting } \\
\text { horizons }\end{array}$ & $R W$ & $H A R$ & $H A R_{U S E P U}$ & $\frac{H_{\text {UAR }}{ }^{a}{ }^{a}{ }^{2}}{R W}$ & $\frac{H_{A A R_{U S E P U}}{ }^{a}}{H A R}$ \\
\hline 1 & 139.0763 & 47.7326 & 51.3075 & 0.3689 & 1.0749 \\
2 & 141.0662 & 104.3545 & 90.2990 & 0.6401 & 0.8653 \\
3 & 136.9169 & 132.7897 & 139.1503 & 1.0163 & 1.0479 \\
4 & 133.6481 & 138.8830 & 127.5426 & 0.9543 & 0.9183 \\
5 & 107.5744 & 123.7463 & 173.3988 & 1.6119 & 1.4012 \\
6 & 83.0601 & 99.5721 & 140.8121 & 1.6953 & 1.4142 \\
7 & 77.5165 & 97.9840 & 123.1823 & 1.5891 & 1.2572 \\
8 & 74.8428 & 98.0214 & 121.8113 & 1.6276 & 1.2427 \\
9 & 75.3276 & 98.6540 & 135.0965 & 1.7935 & 1.3694 \\
10 & 75.7115 & 118.3759 & 131.8561 & 1.7416 & 1.1139 \\
11 & 73.2832 & 150.8982 & 118.5396 & 1.6176 & 0.7856 \\
12 & 71.3890 & 162.0641 & 358.2310 & 5.0180 & 2.2104 \\
\hline
\end{tabular}

${ }^{\alpha}$ A ratio below one suggests that the $H A R_{U S E P U}$ model performs better relatively to the $R W$ or the HAR model. 


\section{FIGURES}

Figure 1: Net pairwise spillover effects between OVX and uncertainty indicators.

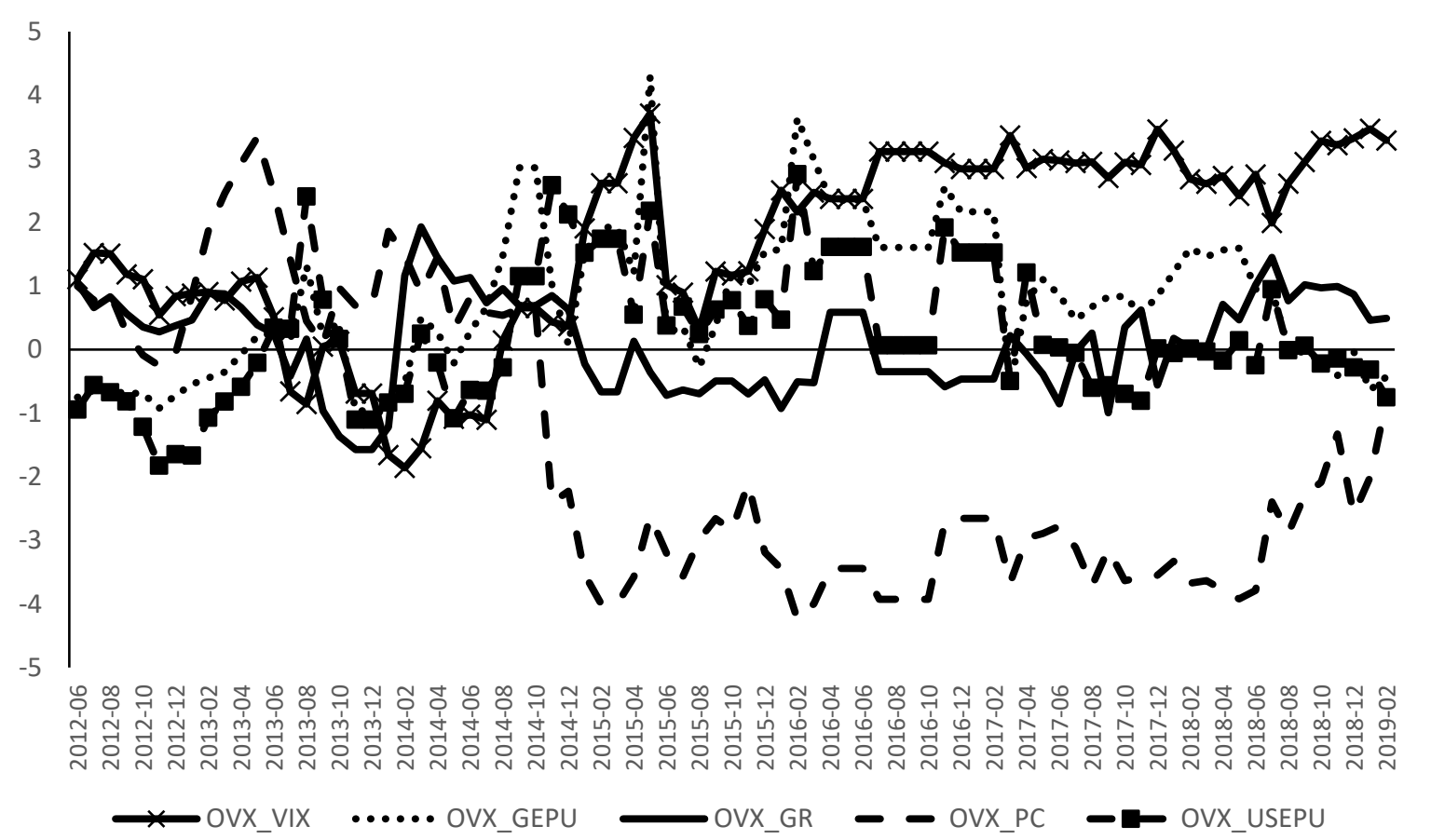

Note: OVX is a net transmitter (receiver) of spillover effects when the line is above (below) the zero line. 


\section{A. Supplementary material (for the benefit of the reviewers)}

As we mentioned in footnote 3 of the paper, the results remain qualitatively similar with those of the HAR model, even when we estimate the in-sample and real out-ofsample forecasts based on autoregressive or distributed lag models. In this supplementary material we present these results for the benefit of the reviewers.

Autoregressive $(A R)$ model:

$$
\begin{gathered}
\log \left(O V X_{t}\right)=\alpha_{0}+\alpha_{1} \log \left(U N C_{t-h}\right)+\alpha_{2} d\left(N P W S_{O V X-U N C, t-h}<0\right) \\
+\alpha_{3} d\left(N P W S_{O V X-U N C, t-h}<0\right) \times \log \left(U N C_{t-h}\right)+e_{t}, \\
e_{t}=\alpha_{4} e_{t-1}+\varepsilon_{t} \\
\varepsilon_{t} \sim\left(0, \sigma_{\varepsilon}^{2}\right)
\end{gathered}
$$

Table A.1: Estimated results from autoregressive model.

\begin{tabular}{lrrrrr}
\hline & \multicolumn{5}{c}{ Uncertainty indicators } \\
\cline { 2 - 6 } & \multicolumn{1}{c}{ VIX } & USEPU & GEPU & \multicolumn{1}{c}{ GR } & \multicolumn{1}{c}{ PC } \\
\cline { 2 - 6 }$\alpha_{0}$ & $3.3774^{* * *}$ & $4.1537^{* * *}$ & $3.4382^{* * *}$ & $3.0397^{* * *}$ & $2.4159^{* *}$ \\
$\alpha_{1}$ & 0.0175 & -0.1641 & -0.0045 & 0.0778 & 0.1911 \\
$\alpha_{2}$ & 0.895 & $-2.1939^{* *}$ & -0.7404 & 0.4395 & 1.3241 \\
$\alpha_{3}$ & -0.3442 & $0.4686^{* *}$ & 0.1462 & -0.0854 & -0.248 \\
$\alpha_{4}$ & $0.8669^{* * *}$ & $0.8702^{* * *}$ & $0.8623^{* * *}$ & $0.8687^{* * *}$ & $0.8518^{* * *}$ \\
\hline Adjusted $R^{2}$ & 0.7575 & 0.7689 & 0.7561 & 0.7565 & 0.7572 \\
$F$-statistic & $50.3677^{* * *}$ & $53.5856^{* * *}$ & $49.9702^{* * *}$ & $50.1088^{* * *}$ & $50.2924^{* * *}$ \\
$D W$ & 1.7241 & 1.7044 & 1.7481 & 1.7156 & 1.7733 \\
AIC & -0.6329 & -0.6808 & -0.6272 & -0.6288 & -0.6331 \\
\hline Note: DW is the Durbin-Watson statistic, AIC is the Akaike Information Criterion. VIX, \\
USEPU, GEPU, GR and PC denote the uncertainty indices for the S\&P500, US economic \\
policy uncertainty, global economic policy uncertainty, geopolitical risk and partisan \\
conflict, respectively. \\
$*{ }^{* * *},{ }^{* * * *}$ denote significance at 10\%, 5\% and 1\% level, respectively. \\
\hline
\end{tabular}

Table A.2: MSPE results from the real out-of-forecasts based on the autoregressive model. Forecasting period: October 2015 - February 2019.

\begin{tabular}{cccccc}
\hline $\begin{array}{c}\text { Forecasting } \\
\text { horizons }\end{array}$ & $R W$ & $A R$ & $A R_{U S E P U}$ & $\frac{A R_{U S E P U}{ }^{a}}{R W}$ & $\frac{A R_{U S E P U}{ }^{a}}{A R}$ \\
\hline 1 & 139.0763 & 42.0779 & 52.0353 & 0.3741 & 1.2366 \\
2 & 141.0662 & 80.5150 & 75.8224 & 0.5375 & 0.9417 \\
3 & 136.9169 & 94.7294 & 91.3651 & 0.6673 & 0.9645 \\
4 & 133.6481 & 94.7242 & 95.2508 & 0.7127 & 1.0056 \\
5 & 107.5744 & 80.2114 & 78.5932 & 0.7306 & 0.9798 \\
6 & 83.0601 & 63.2619 & 65.3242 & 0.7865 & 1.0326 \\
7 & 77.5165 & 60.8114 & 64.7823 & 0.8357 & 1.0653 \\
8 & 74.8428 & 61.1766 & 61.4119 & 0.8205 & 1.0038 \\
9 & 75.3276 & 62.4810 & 65.0116 & 0.8631 & 1.0405 \\
10 & 75.7115 & 73.9098 & 79.1759 & 1.0458 & 1.0713 \\
11 & 73.2832 & 86.7276 & 92.0832 & 1.2565 & 1.0618 \\
12 & 71.3890 & 89.6272 & 95.3667 & 1.3359 & 1.0640 \\
\hline
\end{tabular}

${ }^{\alpha}$ A ratio below one suggests that the $A R_{U S E P U}$ model performs better relatively to the $R W$ or the $A R$ model. 
Distributed lag $(D L)$ model:

$$
\begin{aligned}
& \log \left(O V X_{t}\right)= \alpha_{0}+\alpha_{1} \log \left(U N C_{t-h}\right)+\alpha_{2} d\left(N P W S_{O V X-U N C, t-h}<0\right) \\
&+\alpha_{3} d\left(N P W S_{O V X-U N C, t-h}<0\right) \times \log \left(U N C_{t-h}\right) \\
&+\alpha_{4} \log \left(O V X_{t-1}\right)+\varepsilon_{t}, \\
& \varepsilon_{t} \sim\left(0, \sigma_{\varepsilon}^{2}\right)
\end{aligned}
$$

Table A.3: Estimated results from the distributed lag model.

\begin{tabular}{lrrrrr}
\hline & \multicolumn{5}{c}{ Uncertainty indicators } \\
\cline { 2 - 6 }$\alpha_{0}$ & VIX & USEPU & GEPU & \multicolumn{1}{c}{ GR } & \multicolumn{1}{c}{ PC } \\
\cline { 2 - 6 }$\alpha_{1}$ & $0.5816^{* *}$ & $2.3782^{* * *}$ & $0.8227^{* * *}$ & 0.0691 & 1.1674 \\
$\alpha_{2}$ & 0.0165 & $-0.3705^{* *}$ & -0.0713 & 0.0702 & -0.1095 \\
$\alpha_{3}$ & 0.9835 & $-1.7649^{* *}$ & -0.6928 & 0.2358 & 0.5972 \\
$\alpha_{4}$ & -0.4119 & $0.3612^{* *}$ & 0.1315 & -0.049 & -0.1021 \\
\hline Adjusted $R^{2}$ & $0.8205^{* * *}$ & $0.8214^{* * *}$ & $0.8650^{* * *}$ & $0.8800^{* * *}$ & $0.8050^{* * *}$ \\
$F$-statistic & 0.7698 & 0.7884 & 0.7621 & 0.7588 & 0.7681 \\
$D W$ & $67.0455^{* * *}$ & $74.6001^{* * *}$ & $64.2762^{* * *}$ & $63.1447^{* * *}$ & $66.4045^{* * *}$ \\
AIC & 1.6877 & 1.9356 & 1.7926 & 1.7679 & 1.8161 \\
\hline Note: DW is the Durbin-Watson statistic, AIC is the Akaike Information Criterion. VIX, \\
USEPU, GEPU, GR and PC denote the uncertainty indices for the S\&P500, US economic \\
policy uncertainty, global economic policy uncertainty, geopolitical risk and partisan \\
conflict, respectively. \\
$*$ ***,*** denote significance at 10\%, 5\% and 1\% level, respectively. \\
\hline
\end{tabular}

Table A.4: MSPE results from the real out-of-forecasts based on the DL. Forecasting period: October 2015 - February 2019.

\begin{tabular}{cccccc}
\hline $\begin{array}{c}\text { Forecasting } \\
\text { horizons }\end{array}$ & $R W$ & $D L$ & $D L_{\text {USEPU }}$ & $\frac{D L_{U S E P U}{ }^{a}}{R W}$ & $\frac{D L_{U S E P U}{ }^{a}}{D L}$ \\
\hline 1 & 139.0763 & 42.7974 & 43.7381 & 0.3145 & 1.0220 \\
2 & 141.0662 & 83.4373 & 76.9663 & 0.5456 & 0.9224 \\
3 & 136.9169 & 99.6763 & 113.5156 & 0.8291 & 1.1388 \\
4 & 133.6481 & 100.8561 & 101.3804 & 0.7586 & 1.0052 \\
5 & 107.5744 & 86.3938 & 94.3582 & 0.8771 & 1.0922 \\
6 & 83.0601 & 68.7852 & 71.9800 & 0.8666 & 1.0464 \\
7 & 77.5165 & 66.1093 & 68.1611 & 0.8793 & 1.0310 \\
8 & 74.8428 & 65.7583 & 77.9542 & 1.0416 & 1.1855 \\
9 & 75.3276 & 65.9992 & 140.6598 & 1.8673 & 2.1312 \\
10 & 75.7115 & 80.1259 & 113.4930 & 1.4990 & 1.4164 \\
11 & 73.2832 & 97.6687 & 98.4676 & 1.3437 & 1.0082 \\
12 & 71.3890 & 102.0121 & 123.9249 & 1.7359 & 1.2148 \\
\hline
\end{tabular}

${ }^{\alpha}$ A ratio below one suggests that the $D L_{U S E P U}$ model performs better relatively to the $R W$ or the $D L$ model. 